\title{
Convergence analysis of an iterative scheme for Lipschitzian hemicontractive mappings in Hilbert spaces
}

Shin Min Kang ${ }^{1}$, Arif Rafiq ${ }^{2}$ and Sunhong Lee 1* $^{*}$

\section{"Correspondence:}

sunhong@gnu.ac.kr

'Department of Mathematics and

RINS, Gyeongsang National

University, Jinju, 660-701, Korea

Full list of author information is

available at the end of the article

\begin{abstract}
In this paper, we establish strong convergence for the iterative scheme introduced by Sahu and Petruşel associated with Lipschitzian hemicontractive mappings in Hilbert spaces.

MSC: $47 \mathrm{H} 10 ; 47 J 25$

Keywords: iterative scheme; Lipschitzian mappings; hemicontractive mappings; Hilbert spaces
\end{abstract}

\section{Introduction}

Let $H$ be a Hilbert space, and let $T: H \rightarrow H$ be a mapping. The mapping $T$ is called Lipshitzian if there exists $L>0$ such that

$$
\|T x-T y\| \leq L\|x-y\|, \quad \forall x, y \in H .
$$

If $L=1$, then $T$ is called nonexpansive and if $0 \leq L<1$, then $T$ is called contractive. The mapping $T: H \rightarrow H$ is said to be pseudocontractive (see, for example, [1, 2]) if

$$
\|T x-T y\|^{2} \leq\|x-y\|^{2}+\|(I-T) x-(I-T) y\|^{2}, \quad \forall x, y \in H
$$

and it is said to be strongly pseudocontractive if there exists $k \in(0,1)$ such that

$$
\|T x-T y\|^{2} \leq\|x-y\|^{2}+k\|(I-T) x-(I-T) y\|^{2}, \quad \forall x, y \in H .
$$

Let $F(T):=\{x \in H: T x=x\}$, and let $K$ be a nonempty subset of $H$. A mapping $T: K \rightarrow K$ is called hemicontractive if $F(T) \neq \emptyset$ and

$$
\left\|T x-x^{*}\right\|^{2} \leq\left\|x-x^{*}\right\|^{2}+\|x-T x\|^{2}, \quad \forall x \in H, x^{*} \in F(T) .
$$

It is easy to see that the class of pseudocontractive mappings with fixed points is a subclass of the class of hemicontractions. For the importance of fixed points of pseudocontractions, the reader may consult [1].

In 1974, Ishikawa [3] proved the following result.

@ 2013 Kang et al:; licensee Springer. This is an Open Access article distributed under the terms of the Creative Commons Attribution License (http://creativecommons.org/licenses/by/2.0), which permits unrestricted use, distribution, and reproduction in any medium, provided the original work is properly cited. 
Theorem 1.1 Let $K$ be a compact convex subset of a Hilbert space $H$, and let $T: K \rightarrow K$ be a Lipschitzian pseudocontractive mapping.

For arbitrary $x_{1} \in K$, let $\left\{x_{n}\right\}$ be a sequence defined iteratively by the Ishikawa iterative scheme

$$
\left\{\begin{array}{l}
x_{n+1}=\left(1-\alpha_{n}\right) x_{n}+\alpha_{n} T y_{n}, \\
y_{n}=\left(1-\beta_{n}\right) x_{n}+\beta_{n} T x_{n}, \quad n \geq 1,
\end{array}\right.
$$

where $\left\{\alpha_{n}\right\}$ and $\left\{\beta_{n}\right\}$ are sequences satisfying the conditions

(i) $0 \leq \alpha_{n} \leq \beta_{n} \leq 1$;

(ii) $\lim _{n \rightarrow \infty} \beta_{n}=0$;

(iii) $\sum_{n=1}^{\infty} \alpha_{n} \beta_{n}=\infty$.

Then the sequence $\left\{x_{n}\right\}$ converges strongly to a fixed point of $T$.

Another iterative scheme which has been studied extensively in connection with fixed points of pseudocontractive mappings is the $S$-iterative scheme introduced by Sahu and Petruşel [4] in 2011.

In this paper, we establish strong convergence for the $S$-iterative scheme associated with Lipschitzian hemicontractive mappings in Hilbert spaces.

\section{Main results}

We need the following lemma.

Lemma 2.1 [5] For all $x, y \in H$ and $\lambda \in[0,1]$, the following well-known identity holds:

$$
\|(1-\lambda) x+\lambda y\|^{2}=(1-\lambda)\|x\|^{2}+\lambda\|y\|^{2}-\lambda(1-\lambda)\|x-y\|^{2} .
$$

Now we prove our main results.

Theorem 2.2 Let $K$ be a compact convex subset of a real Hilbert space $H$, and let $T: K \rightarrow$ $K$ be a Lipschitzian hemicontractive mapping satisfying

$$
\|x-T y\| \leq\|T x-T y\|, \quad \forall x, y \in K .
$$

Let $\left\{\beta_{n}\right\}$ be a sequence in $[0,1]$ satisfying

(iv) $\sum_{n=1}^{\infty} \beta_{n}=\infty$;

(v) $\lim _{n \rightarrow \infty} \beta_{n}=0$.

For arbitrary $x_{1} \in K$, let $\left\{x_{n}\right\}$ be a sequence defined iteratively by the S-iterative scheme

$$
\left\{\begin{array}{l}
x_{n+1}=T y_{n}, \\
y_{n}=\left(1-\beta_{n}\right) x_{n}+\beta_{n} T x_{n}, \quad n \geq 1 .
\end{array}\right.
$$

Then the sequence $\left\{x_{n}\right\}$ converges strongly to the fixed point of $T$.

Proof From Schauder's fixed point theorem, $F(T)$ is nonempty since $K$ is a compact convex set and $T$ is continuous. Let $x^{*} \in F(T)$. Using the fact that $T$ is hemicontractive, we 
obtain

$$
\left\|T x_{n}-x^{*}\right\|^{2} \leq\left\|x_{n}-x^{*}\right\|^{2}+\left\|x_{n}-T x_{n}\right\|^{2}
$$

and

$$
\left\|T y_{n}-x^{*}\right\|^{2} \leq\left\|y_{n}-x^{*}\right\|^{2}+\left\|y_{n}-T y_{n}\right\|^{2} .
$$

With the help of (2.1), (2.2) and Lemma 2.1, we obtain the following estimates:

$$
\begin{aligned}
\left\|y_{n}-x^{*}\right\|^{2}= & \left\|\left(1-\beta_{n}\right) x_{n}+\beta_{n} T x_{n}-x^{*}\right\|^{2} \\
= & \left\|\left(1-\beta_{n}\right)\left(x_{n}-x^{*}\right)+\beta_{n}\left(T x_{n}-x^{*}\right)\right\|^{2} \\
= & \left(1-\beta_{n}\right)\left\|x_{n}-x^{*}\right\|^{2}+\beta_{n}\left\|T x_{n}-x^{*}\right\|^{2} \\
& -\beta_{n}\left(1-\beta_{n}\right)\left\|x_{n}-T x_{n}\right\|^{2} \\
\leq & \left(1-\beta_{n}\right)\left\|x_{n}-x^{*}\right\|^{2}+\beta_{n}\left(\left\|x_{n}-x^{*}\right\|^{2}+\left\|x_{n}-T x_{n}\right\|^{2}\right) \\
& -\beta_{n}\left(1-\beta_{n}\right)\left\|x_{n}-T x_{n}\right\|^{2} \\
= & \left\|x_{n}-x^{*}\right\|^{2}+\beta_{n}^{2}\left\|x_{n}-T x_{n}\right\|^{2}, \\
\left\|y_{n}-T y_{n}\right\|^{2}= & \left\|\left(1-\beta_{n}\right) x_{n}+\beta_{n} T x_{n}-T y_{n}\right\|^{2} \\
= & \left\|\left(1-\beta_{n}\right)\left(x_{n}-T y_{n}\right)+\beta_{n}\left(T x_{n}-T y_{n}\right)\right\|^{2} \\
= & \left(1-\beta_{n}\right)\left\|x_{n}-T y_{n}\right\|^{2}+\beta_{n}\left\|T x_{n}-T y_{n}\right\|^{2} \\
& -\beta_{n}\left(1-\beta_{n}\right)\left\|x_{n}-T x_{n}\right\|^{2} .
\end{aligned}
$$

Substituting (2.4) and (2.5) in (2.3) we obtain

$$
\begin{aligned}
\left\|T y_{n}-x^{*}\right\|^{2} \leq & \left\|x_{n}-x^{*}\right\|^{2}+\left(1-\beta_{n}\right)\left\|x_{n}-T y_{n}\right\|^{2}+\beta_{n}\left\|T x_{n}-T y_{n}\right\|^{2} \\
& -\beta_{n}\left(1-2 \beta_{n}\right)\left\|x_{n}-T x_{n}\right\|^{2} .
\end{aligned}
$$

Also, with the help of condition $(C)$ and (2.6), we have

$$
\begin{aligned}
\left\|x_{n+1}-x^{*}\right\|^{2}= & \left\|T y_{n}-x^{*}\right\|^{2} \\
\leq & \left\|x_{n}-x^{*}\right\|^{2}+\left(1-\beta_{n}\right)\left\|x_{n}-T y_{n}\right\|^{2}+\beta_{n}\left\|T x_{n}-T y_{n}\right\|^{2} \\
& -\beta_{n}\left(1-2 \beta_{n}\right)\left\|x_{n}-T x_{n}\right\|^{2} \\
\leq & \left\|x_{n}-x^{*}\right\|^{2}+\left\|T x_{n}-T y_{n}\right\|^{2}-\beta_{n}\left(1-2 \beta_{n}\right)\left\|x_{n}-T x_{n}\right\|^{2} \\
\leq & \left\|x_{n}-x^{*}\right\|^{2}+L^{2}\left\|x_{n}-y_{n}\right\|^{2}-\beta_{n}\left(1-2 \beta_{n}\right)\left\|x_{n}-T x_{n}\right\|^{2} \\
= & \left\|x_{n}-x^{*}\right\|^{2}+L^{2} \beta_{n}^{2}\left\|x_{n}-T x_{n}\right\|^{2}-\beta_{n}\left(1-2 \beta_{n}\right)\left\|x_{n}-T x_{n}\right\|^{2} \\
= & \left\|x_{n}-x^{*}\right\|^{2}-\beta_{n}\left(1-\left(2+L^{2}\right) \beta_{n}\right)\left\|x_{n}-T x_{n}\right\|^{2} .
\end{aligned}
$$

Now, by $\lim _{n \rightarrow \infty} \beta_{n}=0$, there exists $n_{0} \in \mathbb{N}$ such that for all $n \geq n_{0}$,

$$
\beta_{n} \leq \frac{1}{2\left(2+L^{2}\right)},
$$


and with the help of (2.8), (2.7) yields

$$
\left\|x_{n+1}-x^{*}\right\|^{2} \leq\left\|x_{n}-x^{*}\right\|^{2}-\frac{1}{2} \beta_{n}\left\|x_{n}-T x_{n}\right\|^{2},
$$

which implies

$$
\frac{1}{2} \beta_{n}\left\|x_{n}-T x_{n}\right\|^{2} \leq\left\|x_{n}-x^{*}\right\|^{2}-\left\|x_{n+1}-x^{*}\right\|^{2},
$$

so that

$$
\frac{1}{2} \sum_{j=N}^{n} \beta_{j}\left\|x_{j}-T x_{j}\right\|^{2} \leq\left\|x_{N}-x^{*}\right\|^{2}-\left\|x_{n+1}-x^{*}\right\|^{2}
$$

The rest of the argument follows exactly as in the proof of theorem of [3]. This completes the proof.

Theorem 2.3 Let $K$ be a compact convex subset of a real Hilbert space $H$, and let $T$ : $K \rightarrow K$ be a Lipschitzian hemicontractive mapping satisfying condition $(C)$. Let $\left\{\beta_{n}\right\}$ be a sequence in $[0,1]$ satisfying conditions (iv) and (v).

Assume that $P_{K}: H \rightarrow K$ is the projection operator of $H$ onto $K$. Let $\left\{x_{n}\right\}$ be a sequence defined iteratively by

$$
\left\{\begin{array}{l}
x_{n+1}=P_{K}\left(T y_{n}\right), \\
y_{n}=P_{K}\left(\left(1-\beta_{n}\right) x_{n}+\beta_{n} T x_{n}\right), \quad n \geq 1 .
\end{array}\right.
$$

Then the sequence $\left\{x_{n}\right\}$ converges strongly to a fixed point of $T$.

Proof The operator $P_{K}$ is nonexpansive (see, e.g., [2]). $K$ is a Chebyshev subset of $H$ so that $P_{K}$ is a single-valued mapping. Hence, we have the following estimate:

$$
\begin{aligned}
\left\|x_{n+1}-x^{*}\right\|^{2} & =\left\|P_{K}\left(T y_{n}\right)-P_{K} x^{*}\right\|^{2} \\
& \leq\left\|T y_{n}-x^{*}\right\|^{2} \\
& \leq\left\|x_{n}-x^{*}\right\|^{2}-\beta_{n}\left(1-\left(2+L^{2}\right) \beta_{n}\right)\left\|x_{n}-T x_{n}\right\|^{2} .
\end{aligned}
$$

The set $K=K \cup T(K)$ is compact, and so the sequence $\left\{\left\|x_{n}-T x_{n}\right\|\right\}$ is bounded. The rest of the argument follows exactly as in the proof of Theorem 2.2 . This completes the proof.

Remark 2.4 In Theorem 1.1, putting $\alpha_{n}=1,0 \leq \alpha_{n} \leq \beta_{n} \leq 1$ implies $\beta_{n}=1$, which contradicts $\lim _{n \rightarrow \infty} \beta_{n}=0$. Hence the $S$-iterative scheme is not the special case of Ishikawa iterative scheme.

Remark 2.5 In Theorems 2.2 and 2.3, condition $(C)$ is not new; it is due to Liu et al. [6]. 
Authors' contributions

All authors read and approved the final manuscript.

\section{Author details}

'Department of Mathematics and RINS, Gyeongsang National University, Jinju, 660-701, Korea. ${ }^{2}$ School of CS and Mathematics, Hajvery University, 43-52 Industrial Area, Gulberg-III, Lahore, 54660, Pakistan.

\section{Acknowledgements}

The authors would like to thank the referees for useful comments and suggestions.

\section{Received: 24 October 2012 Accepted: 9 March 2013 Published: 27 March 2013}

\section{References}

1. Browder, FE: Nonlinear operators and nonlinear equations of evolution in Banach spaces. In: Nonlinear Functional Analysis. Am. Math. Soc., Providence (1976)

2. Browder, FE, Petryshyn, WV: Construction of fixed points of nonlinear mappings in Hilbert spaces. J. Math. Anal. Appl. 20, 197-228 (1967)

3. Ishikawa, S: Fixed point by a new iteration method. Proc. Am. Math. Soc. 44, 147-150 (1974)

4. Sahu, DR, Petruşel, A: Strong convergence of iterative methods by strictly pseudocontractive mappings in Banach spaces. Nonlinear Anal. 74,6012-6023 (2011)

5. Xu, HK: Inequalities in Banach spaces with applications. Nonlinear Anal. 16, 1127-1138 (1991)

6. Liu, Z, Feng, C, Ume, JS, Kang, SM: Weak and strong convergence for common fixed points of a pair of nonexpansive and asymptotically nonexpansive mappings. Taiwan. J. Math. 11, 27-42 (2007)

doi:10.1186/1029-242X-2013-132

Cite this article as: Kang et al.: Convergence analysis of an iterative scheme for Lipschitzian hemicontractive mappings in Hilbert spaces. Journal of Inequalities and Applications 2013 2013:132.

\section{Submit your manuscript to a SpringerOpen ${ }^{\circ}$ journal and benefit from:}

- Convenient online submission

Rigorous peer review

- Immediate publication on acceptance

- Open access: articles freely available online

- High visibility within the field

- Retaining the copyright to your article 